\title{
Electricity Spot Prices Structural Changes in the Iberian Electricity Market
}

\author{
João Bolas \\ ISEL \\ Lisbon, Portugal \\ A37417@alunos.isel.pt
}

\author{
Jorge Sousa, MIEEE \\ ISEL \\ INESC-ID \\ Lisbon, Portugal \\ jsousa@deea.isel.ipl.pt
}

\author{
Ana Martins \\ ISEL \\ BRU-UNIDE \\ Lisbon, Portugal \\ anamartins@adm.isel.pt
}

\author{
João Lagarto \\ ISEL \\ INESC-ID \\ MIT-Portugal \\ Lisbon, Portugal \\ jlagarto@deea.isel.ipl.pt
}

\begin{abstract}
In recent years, the power sector has undergone a restructuring process in many economies in the world. This movement towards liberalization led to the establishment of electricity markets that promote the competitiveness of the production and trading segments of the power sector.

In these markets, the agents have to deal with frequent electricity price changes leading to different strategies in their daily bidding behavior.

There are a set of variables that can have an impact in the electricity price definition, such as: fuel prices, $\mathrm{CO}_{2}$ emissions prices, electricity production and demand.

This paper proposes to analyze structural changes in the Iberian electricity market price between two periods of time: 2007/2008 and 2010/2011. For this purpose, three quantitative analysis methods were used: correlation, causality and Principal Components.

Results suggest that the electricity price had a structural change between the analyzed periods, in particular the increasing importance of special regime production.
\end{abstract}

Index Terms--Correlation, Electricity price, MIBEL, Principal components

\section{INTRODUCTION}

Electricity is a tradable commodity. For the purpose of trading electricity, markets like the Iberian electricity market (MIBEL) were created.

MIBEL was formed by the integration of the electrical systems of Portugal and Spain. This market came into operation in July 1, 2007 allowing free access to the electricity market for all the players in the Iberian Peninsula.

The introduction of a competitive electricity market should bring about efficiency gains, which would lead to more cost reflexive electricity prices to consumers. However, electricity prices, in this type of markets, experience frequent daily fluctuations [1]. Due to the electricity characteristics, these prices are extremely volatile and influenced by many variables such as demand, fuel prices, hydro and other renewable production, market agents behavior and $\mathrm{CO}_{2}$ emission prices [2]. According to [3], electricity prices volatility should be a major concern for the markets participants, since it is related with an uncertainty in terms of investment and power plants management. Hence, it is important to have thorough knowledge, about these variables, knowing which one of them

This work was supported by national funds through FCT - Fundação para a Ciência e a Tecnologia, under project PEst-OE/EEI/UI4064/2011. has most influence in electricity price definition. This allows the development of efficient electricity price forecasting techniques.

Electricity prices are dependent of the power plants that are in operation, since a higher demand of thermal production will implies that more expensive power plants come into operation, increasing the production costs and, consequently, increasing the electricity prices [4]. According to [5], in the Italian electricity market, regions like Sicily and Sardinia, the electricity price was extremely influenced by the generations levels of coal power plants and, consequently, by coal prices. In north and center regions, the natural gas caused an increase in electricity prices. With this study, the authors aimed at understanding electricity price and volatility dynamics for production planning, production pricing and risk-hedging problems.

As mentioned previously, $\mathrm{CO}_{2}$ emission prices have influence in electricity price. In [6] and [7] results showed that the incorporation of $\mathrm{CO}_{2}$ emission costs would increase the electricity prices, in the Italian and Greek electricity markets.

With the fossil fuels predictable depletion along with climate change concerns and the controversy around the nuclear energy, the renewable energies are seen as the main source of energy in the future. With the increasing generation levels from renewable sources a decrease in the electricity prices should be expected. According to [8], in the Dutch electricity market, the wind production levels had a substantial impact in the electricity prices. Despite the reduced contribution of the wind production in the total country production, the electricity market price decreased.

In [9], the authors used data mining techniques, based on data grouping (clusters) and decision trees, in order to study the electricity price, in the Brazilian electricity market. The authors concluded that hydro and thermal productions had a considerable impact in setting the electricity market price.

Some studies have showed that some producers have a capacity for potential abuse of market power, as for example [10], [11], and [12]. In [10], evidence that suppliers have the potential ability to abuse market power has been showed. With this abuse of market power, producers may have had substantial revenues. In order to study this problem, quantitative analysis methods were applied on the variables that showed an influence in the electricity market price. The applications of multivariate models, such as correlation, 
reliability, factor analysis, and cluster analysis, among others were also applied. With this methodology, it was possible to detect collusion situations and identify the supplier's strategies and interpret their profit margin.

An a priori analysis of the electricity prices is a crucial step in order to develop forecasting techniques. For example, in [13], [14] and [15], the study of forecasting techniques is only possible after an analysis of the electricity price.

This paper proposes to analyze possible electricity price structural changes, in the MIBEL. The importance of special regime production (where renewable energy is included) on electricity price definition is also analyzed. For this purpose, three quantitative analysis methods were used: correlation analysis (Pearson's correlation) causality analysis (Granger causality) and Principal Components Analysis (PCA).

This paper is organized as follows. Section II describes the methodology used to develop this study. Section III shows the obtained results and, finally in Section IV conclusions are presented.

\section{METHODOLOGY}

As mentioned before, three quantitative analysis methods were used enabling some conclusions about which variables had a considerable impact in electricity price definition and, also, verify if there were possible electricity price structural changes.

\section{A. Correlation analysis}

The first method used is correlation analysis. With this, it is possible to screen out the variables that reveal a higher contribute to the electricity price definition. For this purpose, it was used the Pearson's correlation coefficient and it can be represented by the follow expression

$$
r=\frac{1}{n} \frac{\stackrel{n}{\square}\left(x_{i}-\bar{X}\right) \times\left(y_{i}-\bar{Y}\right)}{S(X) \times S(Y)}
$$

As shown in (1), the Pearson's sample coefficient of linear correlation $(r)$ is obtained by the quotient between the covariance of the two variables $(X$ and $Y$ ) and the product of each standard deviation.

In spite of referring to a measure of the relationship between two variables, it does not take into account the time lagged values of the variables.

\section{B. Granger causality analysis}

The Granger causality test is performed. This test consists in identifying the significance of the regression coefficients of lagged values of $\mathrm{X}$ and $\mathrm{Y}$ on future values of $\mathrm{Y}$. The regression equation is described by (2).

$$
Y_{t}=\alpha+\sum_{j=1}^{p} \beta_{1 j} Y_{t-j}+\sum_{j=1}^{p} \beta_{2 j} X_{t-j}+n_{t}
$$

Where: $Y_{t}$ and $X_{t}$ are the test variables, $\alpha$ is a estimated coefficient model, $\beta$ are estimated coefficients of variables, $j$ are the lag values, $p$ are the maximum number of lag values and $n_{t}$ is the errors (or innovation) set. In this study, $p=2$.

When there is a dependency relationship between the two variables, the coefficients $\beta_{2 j}$ have to be significant.

\section{Principlal Components Analysis}

The third method used is PCA. This method allows reducing data dimension. Therewith, it is possible to deliver a precaution decision, by monitoring a small number of variables.

PCA is a multivariate procedure. From an initial set of variables, using PCA, it is possible to obtain a smaller set of variables, these being mutually orthogonal or uncorrelated [16]. For that, a process of rotation is applied. The main objective is to obtain the maximum variance with the new set of variables. The new variables are defined as Principal Components (PC) and are linear combinations of the initial variables, as follows:

$$
\begin{gathered}
Y_{1}=a_{11} X_{1}+a_{21} X_{2}+\cdots+a_{p 1} X_{p} \\
Y_{2}=a_{21} X_{1}+a_{22} X_{2}+\cdots+a_{p 2} X_{p} \\
\vdots \\
Y_{m}=a_{1 m} X_{1}+a_{2 m} X_{2}+\cdots+a_{p m} X_{p}
\end{gathered}
$$

where $m$ represents the number of $\mathrm{PC}$ and $p$ the number of variables. In order to obtain a smaller set of variables $m$ should be less or equal to $p(m \leq p)$.

Equation (3) shows that an associated error does not exist. This is a characteristic of PCA, because the variables are measured without error and latent variables are perfectly linear combinations of the initial variables.

The quantity of variance that is explained by each PC is sorted in decreasing order. The first PC explains the higher quantity of variance. The second PC explains a certain quantity of variance, that hasn't been explained by the first one, and so on, until a good enough amount of explained variance is obtained [16].

As an example of work that used PCA to study electricity markets is [17] where the authors used this type of analysis to select the most important input variables for the fuzzy regression and time series models used to forecast electricity consumption in the Iranian electricity market.

Also in [18], the authors used an approach based on PCA to obtain parameters of an optimization model for consumption scheduling when there is a high correlation of prices in different periods.

\section{Case study}

The main objective proposed by this study is an electricity price structural analysis in the MIBEL, using three quantitative analysis methods: correlation, causality and PCA. With these, the intention was to find possible structural changes in the electricity price, identifying which variables reveal a higher impact in price definition and, also, to reach a smaller set of uncorrelated variables, which present a considerable, contribute for price definition. 
The initial set consists in a total of twenty variables, in a daily basis, as follows:

- Fuel prices related to electricity production - Brent, coal (API 2 and API 4), fuel (1\% and 3,5\% of Sulfur) and natural gas (NBP, Henry Hub and Zeebrugge);

- $\mathrm{CO}_{2}$ emissions price;

- Conjectural variation of the market;

- Demand;

- Exchange rates EUR-USD and EUR-GBP;

- Thermal power capacity, reserve margin and electricity production (thermal, hydro, special regime, undefined and others).

Conjectural variation of the market represents the level of competitiveness of the market companies (see [2]). Undefined represents the production values from MIBEL producers whose production technology is unknown. Others represent the production values from MIBEL smaller producers.

Table I presents each variable and its abbreviation.

TABLE I - VARIABLES AND ABBREVIATIONS

\begin{tabular}{|cc|}
\hline Variables & Abbreviations \\
\hline${\text { Coal } \mathrm{API}_{2}}$ & $\mathrm{API}_{2}$ \\
\hline Coal $\mathrm{API}_{4}$ & $\mathrm{API}_{4}$ \\
\hline Henry Hub & $\mathrm{HH}$ \\
\hline $\mathrm{NBP}$ & $\mathrm{NBP}$ \\
\hline Zeebrugge & $\mathrm{Zee}$ \\
\hline Fuel $_{1 \%}$ & $\mathrm{Fu}_{1 \%}$ \\
\hline Fuel $_{3.5 \%}$ & $\mathrm{Fu}_{3.5}$ \\
\hline Brent & $\mathrm{Bnt}$ \\
\hline $\mathrm{CO}_{2}$ & $\mathrm{CO}_{2}$ \\
\hline Exchange Rate EUR-USD & $\mathrm{ER}_{\mathrm{E}-\mathrm{U}}$ \\
\hline Exchange Rate EUR-GBP & $\mathrm{ER}_{\mathrm{E}-\mathrm{G}}$ \\
\hline Conjectural Variation of the Market & $\mathrm{CVM}$ \\
\hline Demand & $\mathrm{Dmd}$ \\
\hline Thermal Power Capacity & $\mathrm{TPC}$ \\
\hline Thermal Reserve Margin & $\mathrm{TRM}$ \\
\hline Thermal Production & $\mathrm{TP}$ \\
\hline Hydro Production & $\mathrm{HP}$ \\
\hline Special Regime Production & $\mathrm{SRP}$ \\
\hline Undefined Production & $\mathrm{UP}$ \\
\hline Others Production & $\mathrm{OP}$ \\
\hline
\end{tabular}

To develop this study two different periods of time were selected. The first one is from July 1, 2007 to June 30, 2008 (the first year of operation of the MIBEL), and the second one from November 1, 2010 to October 30, 2011.

\section{RESULTS}

By the correlation analysis it was possible to evaluate which variables revealed to be more correlated with the electricity prices. In Table II it is possible to see this aspect for each period of time.

The results presented in table II, suggest that a structural change in the electricity price has occurred between the two periods of time.

In $2007 / 2008$, it is clear that the electricity price was mostly dependent on fuel prices and demand values. For this case, it was obtained higher values for the correlation coefficient, namely: Zeebrugge, coal API 4, NBP, among others.

In $2011 / 2012$, it is noted that the tendency for the electricity price to be dependent on fuel prices was not verified. In this case, the electricity price was more dependent on electricity production values and $\mathrm{CO}_{2}$ emission prices. In this case, the coefficient values turned out to be lower than in 2007/2008. However, variables like thermal production, thermal reserve margin and special regime production presented the highest values.

TABle II - CORRELATION ReSUlts FOR BOTH PERIODS

\begin{tabular}{|ccc|}
\hline Variables & $\mathbf{2 0 0 7 / 2 0 0 8}$ & $\mathbf{2 0 1 0} / \mathbf{2 0 1 1}$ \\
\hline Zeebrugge & 0.811 & 0.218 \\
\hline Coal API $_{+}$ & 0.770 & -0.037 \\
$\mathrm{NBP}$ & 0.746 & 0.003 \\
\hline Coal API $_{2}$ & 0.704 & 0.140 \\
Demand & 0.699 & 0.039 \\
Fuel $_{1 \%}$ & 0.598 & 0.379 \\
\hline Brent $_{\text {Henry Hub }}$ & 0.555 & 0.337 \\
\hline Thermal production & 0.543 & -0.192 \\
\hline Thermal reserve margin & 0.543 & 0.558 \\
\hline Special regime production & -0.510 & -0.552 \\
\hline Undifined produciton & 0.045 & -0.543 \\
\hline CO & 0.709 & -0.543 \\
\hline Hydro production & 0.331 & -0.484 \\
\hline & -0.442 & -0.390 \\
\hline
\end{tabular}

Fig. 1 is a graphic representation of the results obtained in Table II.

Analyzing Fig. 1, it can be concluded in the first year of operation of the MIBEL (2007/2008), the electricity price was dependent, mostly, on fuel prices. After three years of operation (2010/2011), the electricity price revealed a higher dependency on electrical production values, in which the production from special regime has revealed a substantial increase. This aspect, allows the conclusion that the production by renewables means is increasingly important for electricity price definition, in MIBEL. 


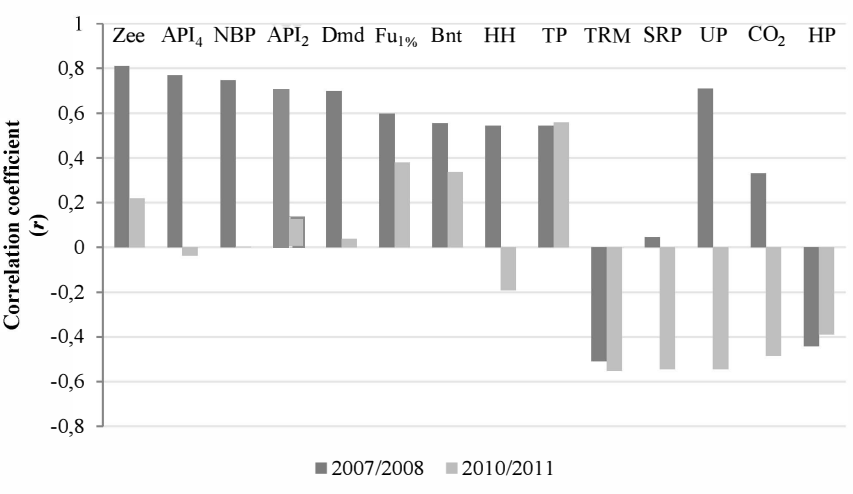

Figure 1 - Correlation coefficients for both periods

Another important aspect was the fact that, after three years of operation, the demand was less important for electricity price definition. In 2007/2008 it was one of the most important variables for price definition, whereas in 2010/2011, this aspect was not verified, since the correlation coefficient was 0.039 . This was due to the increasing importance that the special regime production levels has in setting the electricity price.

Other interesting point was that from one period to another, the correlation coefficient values have, in general, decreased, as it can be seen in Fig. 1.

The main purpose of performing the causality tests was to complementing the results obtained by the correlation analysis. In general, the results obtained by the two methods (correlation and causality) revealed a high concordance and coherence. These results are presented in Fig. 2.

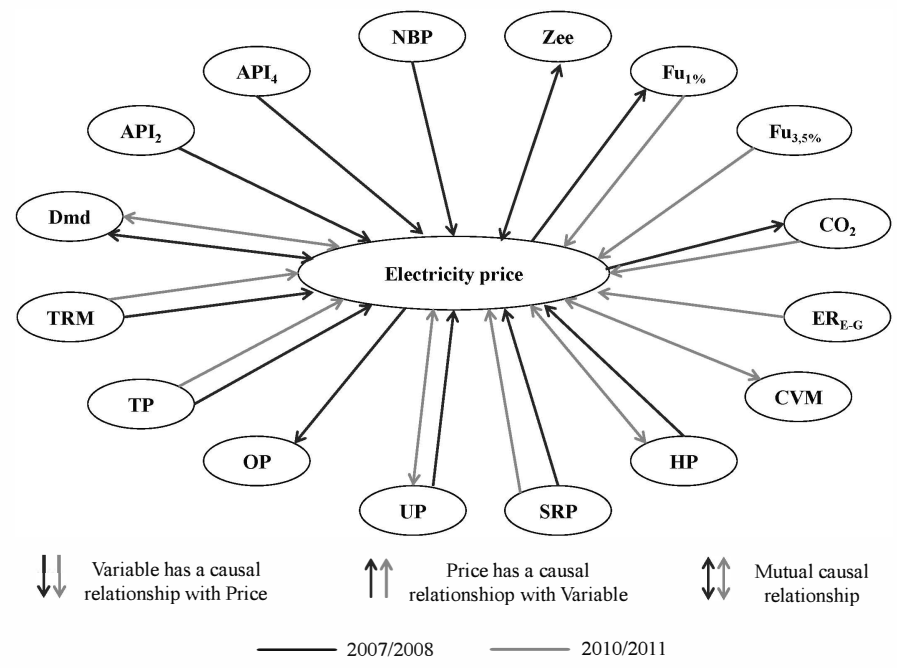

Figure 2 - Causality results for both periods

As Fig. 2 shows, in 2007/2008 the tendency for fuel prices, along with electricity production, to be highly related to the electricity price remained. For example: coal API 2, API 4 and natural gas NBP had a causal relationship with electricity price; natural gas Zeebrugge had a mutual causal relationship with electricity price; electricity price had a causal relationship with fuel price with $1 \%$.

In 2010/2011 the electricity price presented, once again, a causal relationship with electrical production values, where: thermal production and special regime production had a causal relationship with electricity price; undefined and hydro production had a mutual relationship with electricity price. $\mathrm{CO}_{2}$ emissions price had also a causal relationship with electricity price.

However, there are some variables that did not have any kind of causal relationship with electricity price, such as: Brent Henry Hub, exchange rate EUR-USD and thermal power capacity.

In order to reduce the dimension of the initial set of twenty variables the PCA process was used. From the initial set, it was possible to obtain a new set, with lower dimension and mutually uncorrelated variables. According to [19], there are many empirical rules to choose an amount of PC, which enables to obtain good results, such as: an amount of cumulative explained variance between $70 \%$ and $90 \%$; when the curve of the scree plot (graphic representation of the explained variance by PC) is, practically, parallel with the $\mathrm{x}$ axis, the principal components after that can be neglected.

In Table III, the amount of explained variance and cumulative explained variance is presented, in percentage, referred to each PC (highlighted in bold), for 2007/2008. It can be seen, that the initial set was reduced for 5 principal components. With this PC number, it was possible to explain an amount of $92.86 \%$ of cumulative variance

TABLE III - AMOUNT OF VARIANCE FOR 2007/2008

\begin{tabular}{|ccc|}
\hline Component & \% Variance & \% Cumulative Variance \\
\hline 1 & 59.73 & 59.73 \\
2 & 19.53 & 79.26 \\
3 & 5.54 & 84.80 \\
4 & 4.73 & 89.53 \\
$\mathbf{5}$ & $\mathbf{3 . 3 3}$ & $\mathbf{9 2 . 8 6}$ \\
6 & 2.98 & 95.84 \\
\hline
\end{tabular}

In Table IV, the amount of explained variance and cumulative explained variance is presented, in percentage, referred to each PC (highlighted in bold), for 2010/2011. In this case, the initial set was reduced to 8 principal components and an amount of $92.94 \%$ of cumulative variance was achieved.

TABLE IV - AMOUNT OF VARIANCE FOR 2010/2011

\begin{tabular}{|ccc|}
\hline Component & \% Variance & \% Cumulative Variance \\
\hline 1 & 33.06 & 33.06 \\
2 & 16.72 & 49.78 \\
3 & 13.86 & 63.64 \\
4 & 8.27 & 71.91 \\
5 & 7.87 & 79.78 \\
6 & 4.93 & 84.71 \\
7 & 4.22 & 88.93 \\
$\mathbf{8}$ & $\mathbf{4 . 0 1}$ & $\mathbf{9 2 . 9 4}$ \\
9 & 1.75 & 94.69 \\
\hline
\end{tabular}


Despite being usual to obtain good results for values of cumulative variance higher than $75 \%$, it was decided to consider a value grater or equal to $90 \%$. This was because, with $75 \%$ of variance the amount of retain PC was small, what could bring robustness problems for the analysis.

Through that, the main objective was achieved. In other words, it was possible to reduce the dimension of the initial set of variables. The fact that, in the different periods of time, sets with different dimensions of PC were obtained reveals that it is possible that there was a structural change in the market.

As mentioned before, each PC is a linear combination of each initial variable. Therefore, it is easy to understand that every PC has a contribution, higher or smaller, from all variables for its definition. However, there are several variables that present a higher contribution for the component definition than others, what can be seen after a rotation process. In both cases, a rotation process named varimax has applied. Table $\mathrm{V}$ presents which variables revealed a higher contribution for each PC definition, for 2007/2008.

TABLE V - PRINCIPAL COMPONENT DEFINITION FOR 2007/2008

\begin{tabular}{|cc|}
\hline Component & Variables \\
\hline 1 & $\begin{array}{c}\text { Brent } \\
\text { Fuel 1\% }\end{array}$ \\
\hline 2 & $\begin{array}{c}\text { Thermal margin reserve } \\
\text { Thermal production } \\
\text { Others } \\
\text { Special regime } \\
\text { Hydro production }\end{array}$ \\
4 & Thermal power capacity \\
\hline
\end{tabular}

Table VI presents which variables revealed a higher contribution for each PC definition, for 2010/2011.

TABLE VI - PRINCIPAL COMPONENT DEFINITION FOR 2010/201 1

\begin{tabular}{|c|c|}
\hline Component & Variables \\
\hline 1 & $\begin{array}{c}\text { Exchange rate EUR-USD } \\
\text { Fuel } 1 \%\end{array}$ \\
\hline 2 & $\begin{array}{c}\text { Coal API } 4 \\
\text { Thermal power capacity }\end{array}$ \\
\hline 3 & $\begin{array}{l}\text { Thermal production } \\
\text { Thermal margin reserve }\end{array}$ \\
\hline 4 & $\begin{array}{c}\text { Undefined } \\
\mathrm{CO}_{2} \text { price emissions }\end{array}$ \\
\hline 5 & $\begin{array}{c}\text { NBP } \\
\text { Zeebrugge }\end{array}$ \\
\hline 6 & $\begin{array}{c}\text { Others } \\
\text { Special regime }\end{array}$ \\
\hline 7 & Henry Hub \\
\hline 8 & $\begin{array}{l}\text { Conjectural variation of } \\
\text { the market }\end{array}$ \\
\hline
\end{tabular}

It is observed in Tables $\mathrm{V}$ and VI that different numbers of PC were obtained and, each PC is composed by different variables. This may prove the existence of structural changes.

Although the variables which compose each PC are correlated with each other, the PC are mutually uncorrelated. With this conclusion, other main objective is achieved. In other words, new sets of uncorrelated variables (PC) were obtained, which are compose by correlated variables that revealed a high impact in price definition.

\section{CONCLUSIONS}

This paper presents three different quantitative analysis methods, in order to evaluate possible electricity price structural changes, in the MIBEL. The presented methods are: correlation analysis, using Pearson's correlation coefficient, causality analysis, using the Granger causality test, and principal components analysis.

Two different periods of time were analyzed. One referred to 2007/2008 (first year of operation of the MIBEL), other referred to 2010/2011 (three years after beginning of operation). From one period to another it was identified possible electricity price structural changes.

Through correlation analysis it was evident that in $2007 / 2008$ fuel prices revealed a very important impact in electricity price. However in 2010/2011, the electricity price showed to be more related with electrical energy production levels, namely thermal production. From one period to another, it was notorious a significant increase of special regime production. This reveals the importance of renewable production in electricity price definition.

It was intended with causality analysis to reinforce the results obtained with correlation analysis. In general, the results obtained by the two methods (correlation and causality) revealed a high concordance and coherence, where: in $2007 / 2008$ the tendency for fuel oil prices, associated with electricity production, to be highly related to the electricity price remains; in 2010/2011 the electricity price presents, once again, a causal relationship with electrical production values and with $\mathrm{CO}_{2}$ emissions price.

By PCA it was possible to reduce the dimension of the initial variables set to only two new variables set: a set with 5 new variables for $2007 / 2008$, with a total of explained variance of $92.86 \%$, and a set with 8 new variables for $2010 / 2011$, with a total of explained variance of $92.94 \%$.

With this paper the possibility of electricity price structural changes in the MIBEL was highlighted. Also, it could give some helpful insights for electricity price forecasting. With these potentialities, it may be possible for producers and consumers to develop a better strategy, in order to increase their own benefits.

Future research will focus on the development of modeling strategies regarding a better understanding of the changes in market price by evaluating the interchanges between the variables that influence the market price. 


\section{REFERENCES}

[1] R. Huisman and M. Kilic, "A history of European electricity day-ahead prices," Applied Economics, pp. 2683-2693, Apr. 2012

[2] J. Lagarto, J. Sousa, A. Martins and P. Ferrão, "Price forecasting in the day-ahead Iberian electricity market using a conjectural variations ARIMA model," in Proc. $20129^{\text {th }}$ International Conference - On The European Energy Market, pp. 1-7.

[3] A. Gianfreda, L. Grossi and D. Olivieri, "Volatility structures of the Italian market: an analysis of leverage and volume effects," in Proc. $20107^{\text {th }}$ International Conference - The European Electricity Market, pp. 1-6.

[4] J. Lima, R. Jerónimo and T. Silva, "Impact of the renewable energy generation on the Iberian electricity market," in Proc. $20085^{\text {th }}$ International Conference - The European Electricity Market, pp. 1-6.

[5] A. Gianfreda and L. Grossi, "Zonal price analysis of the Italian wholesale electricity market," in Proc. $20096^{\text {th }}$ International Conference - The European Electricity Market, pp. 1-6.

[6] A. Abeygunawardana, C. Bovo and A. Berizzi, "Implications of $\mathrm{CO}_{2}$ prices on the generation capacity expansion in the Italian electricity market," in Proc. $201045^{\text {th }}$ International Universities Power Engineering Conference, pp. 1-6.

[7] P. Andrianesis, G. Liberopoulos and P. Biskas, "Impact of emissions cost on the mid-term generation scheguling in the Greek electricty market," in Proc. $20107^{\text {th }}$ Mediterranean Conference and Exibithion on Power Generation, Transmission, Distribution and Energy Conversion, pp. 1-10.

[8] F. Nieuwenhout and A. Brand, "The impact of wind power on day-ahead electricity prices in the Netherlands," in Proc. $20118^{\text {th }}$ International Conference - On The European Energy Market, pp. 226-230.

[9] J. Reston Filho, C. Affonso and R. Oliveira, "Pricing analysis in the Brazilian energy market: a decision tree approach," in Proc. 2009 IEEE Bucharest PowerTech, pp. 1-6.
[10] L. Dun-nan, X. Heng and H. Wang, "Quantitative analysis methods for electricity market," in Proc. 2009 IEEE International Conference on Management and Service Science. MASS '09, pp. 1-4.

[11] A. Abeygunawardana, C. Bovo and A. Berizzi, "Market power analysis in the Italian electricity market using a supply function equilibrium model," in Proc. 2009 IEEE $44^{\text {th }}$ International Universities Power Engineering Conference, pp. 1-5.

[12] V. Marques, I. Soares and A. Fortunato, "Market power and market games: evidence from the Spanish electricity market," in Proc. 2005 International Conference on Future Power Systems, pp. 1-6.

[13] J. Contreras, R. Espínola, F. Nogales and A. Conejo, "ARIMA models to predict next-day electricity prices," IEEE Trans. Power Systems, vol. 18, pp. 1014-1020, Aug. 2003.

[14] A. Conejo, M. Plazas, R. Espínola and A. Molina, "Day-ahead electricity price forecasting using the wavelet transform and ARIMA models," IEEE Trans. Power Systems, vol. 20, pp. 1035-1042, May 2005.

[15] F. Nogales, J. Contreras, A. Conejo and R. Espínola, "Forecasting nextday electricity prices by time series models", IEEE Trans. Power Systems, vol. 17, pp. 342-348, May 2002.

[16] C. Chatfield and A. Collins, Introduction to Multivariate Analysis, $1^{\mathrm{a}}$ edition, Chapman \& Hall, 1980.

[17] A. Azadeh, M. Saberi, A. Gitiforouz, "An integrated fuzzy mathematical model and principal component analysis algorithm for forecasting uncertain trends of electricity consumption," Quality \& Quantity, vol. 47, pp. 2163-2176, Jun. 2013.

[18] R. Ferreira, L. Barroso and M. Carvalho, "Demand response models with correlated price data: A robust optimization approach," Applied Energy, vol. 96, pp. 133-149, Feb. 2012.

[19] B. Everitt and G. Dunn, Applied Multivariate Data Analysis, $2^{\mathrm{a}}$ edition, Arnold Publications Series, 2001. 